\title{
Depression as a predictor of worse quality of life outcomes following nonoperative treatment for lumbar stenosis
}

\author{
Daniel Lubelski, BA, ${ }^{1,2}$ Nicolas R. Thompson, MS, ${ }^{3,4}$ Sachin Bansal, MD, ${ }^{1}$ Thomas E. Mroz, MD,,2 \\ Daniel J. Mazanec, MD, ${ }^{1,2}$ Edward C. Benzel, MD, ${ }^{1,2}$ and Tagreed Khalaf, MD ${ }^{1,2}$ \\ ${ }^{1}$ Cleveland Clinic Center for Spine Health, Cleveland Clinic; ${ }^{2}$ Cleveland Clinic Lerner College of Medicine; ${ }^{3}$ Department of \\ Quantitative Health Sciences, Cleveland Clinic; and ${ }^{4}$ Neurological Institute Center for Outcomes Research and Evaluation, \\ Cleveland Clinic, Cleveland, Ohio
}

\begin{abstract}
OBJECT The goal of this study was to determine whether pretreatment depression is predictive of quality of life (QOL) improvement for patients with lumbar spinal stenosis (LSS) who are treated conservatively.

METHODS This retrospective cohort study included patients with LSS and concordant neurogenic claudication who were treated nonoperatively at a single institution between September 2010 and March 2013. Patient QOL measures were recorded pretreatment and then 4 months after treatment. Pretreatment depression was assessed using the Patient Health Questionnaire-9 (PHQ-9). Successful outcome was defined as posttreatment improvement in EuroQol-5D (EQ-5D) index or in Pain and Disability Questionnaire (PDQ) scores. Regression analysis was performed to identify independent predictors of outcome while controlling for confounding variables.
\end{abstract}

RESULTS A total of 502 patients were included in the study. The average age for these patients was 66.1 years, with $51 \%$ female and $90.6 \%$ white. After adjusting for baseline demographic and clinical variables, there was a statistically significant association between baseline PHQ-9 score and posttreatment change in EQ-5D index $(\beta=-0.007, p=$ 0.0002). All other things being equal, a patient with a baseline PHQ-9 score of 0 (no depression) would be expected to improve in the EQ-5D index by 0.14 points (greater than the minimum clinically important difference) more than would a patient with a baseline PHQ-9 score of 20 (major depression). There was no significant association between baseline PHQ-9 score and change in Pain and Disability Questionnaire scores.

CONCLUSIONS When controlling for other baseline characteristics, severely depressed patients with LSS who are treated nonoperatively have significantly less improvement in their QOL compared with those with little or no depression. These data are similar to the negative predictive effects of depression on posttreatment QOL following lumbar fusion surgery.

http://thejns.org/doi/abs/10.3171/2014.10.SPINE14220

KEY WORDS depression; Patient Health Questionnaire-9; EuroQol-5 Dimensions index; lumbar spinal stenosis; conservative treatment; prediction

L UMBAR spinal stenosis (LSS) is a common diagnosis, occurring in almost half of patients older than 60 years. ${ }^{17}$ Patients with LSS can present with radicular pain or weakness that occurs secondary to narrowing of the lumbar spinal canal. Both medical and surgical treatments are available for LSS. While possibly not as effective as surgical treatment, medical therapy for LSS avoids the numerous surgical risks including infection, blood loss, nerve damage, and death. Conservative treat- ment options typically consist of physical therapy, interventional procedures such as epidural steroid injections, and membrane-stabilizing agents. Early identification of patients who are more likely to improve with conservative management can help lead to better outcomes and reduced costs.

Previous studies have demonstrated a correlation between pretreatment depression and posttreatment pain and disability following lumbar spine surgery. ${ }^{2-4,8,9,21,25,29}$

ABBREVIATIONS BMI = body mass index; EQ-5D = EuroQol-5 Dimensions; LSS = lumbar spinal stenosis; $M C I D=$ minimum clinically important difference; $P D Q=$ Pain and Disability Questionnaire; PHQ-9 = Patient Health Questionnaire-9; QOL = quality of life.

SUBMITTED March 1, 2014. ACCEPTED October 28, 2014

INCLUDE WHEN CITING Published online December 19, 2014; DOI: 10.3171/2014.10.SPINE14220.

DISCLOSURE The authors report no conflict of interest concerning the materials or methods used in this study or the findings specified in this paper. 
Those patients with more severe depression tend to have decreased improvements with lumbar surgery. No studies have investigated the impact of pretreatment psychosocial factors (e.g., depression) on posttreatment outcomes following conservative treatment. In the present study we assessed the impact of pretreatment depression on outcomes following conservative management for LSS. Our hypothesis was that similar to predictors of outcome following surgery, pretreatment depression would be associated with worsened quality of life (QOL) outcomes following medical therapy for LSS.

\section{Methods \\ Study Sample}

A retrospective study of all patients in whom LSS was diagnosed at a single tertiary-care institution between September 2010 and March 2013 and who received nonsurgical management was performed. Nonsurgical management was based on the discretion of the individual medical provider but typically consisted of "usual care," 30 which includes physical therapy, administration of NSAIDs, and membrane-stabilizing agents. The extent of participation with physical therapy or medication treatment and other nonsurgical treatment was not used in the inclusion and exclusion criteria.

Patient data were extracted from the electronic medical records based on the inclusion and exclusion criteria. Inclusion was based on age older than 45 years and a diagnosis of LSS, which would be made based on criteria such as gluteal and/or lower-extremity pain and/or fatigue with or without back pain; symptoms aggravated by upright exercise such as walking or positionally induced neurogenic claudication; and symptomatic relief with forward flexion, sitting, or recumbency. Inclusion was also dependent on pre- and posttreatment participation in the Knowledge Program, an institutional prospectively maintained database embedded in our electronic medical record, in which QOL outcomes measures were collected from all patients at each visit. Exclusion criteria included previous spine surgery as well as patients with spinal tumors, cauda equina syndrome, spinal fracture, epilepsy, and renal failure (Table 1). Education level, median annual household income, and poverty status were calculated based on patients' zip codes (Missouri Census Data Center).

\section{Quality of Life}

The QOL outcomes questionnaires included the Patient Health Questionnaire-9 (PHQ-9), ${ }^{20,27,28}$ Pain Disability Questionnaire (PDQ), ${ }^{12}$ and EuroQol-5 Dimensions (EQ5D). ${ }^{7,14,16}$ For all measures except the EQ-5D, a decrease in score represents improvement. This information has been prospectively collected in the Spine Center since 2009. These data were collected at baseline (before treatment) and at the $4 \pm 2$-month follow-up.

The PHQ-9 was used to assess for pretreatment depression. This questionnaire is a self-administered assessment for depression in patients that evaluates the 9 Diagnostic and Statistical Manual, ed. IV, criteria for major depressive disorder. Each of the 9 questions is scored from 0 ("not at all") to 3 ("nearly every day"), making the total
TABLE 1. Inclusion and exclusion criteria for patients with LSS treated conservatively at the Cleveland Clinic

\begin{tabular}{|c|c|}
\hline Inclusion & Exclusion \\
\hline Age $>45$ yrs & Previous spine surgery \\
\hline $\begin{array}{l}\text { Diagnosis of LSS btwn Sept } 2010 \\
\quad \text { \& March 2013* }\end{array}$ & $\begin{array}{l}\text { Concurrent confounding patholo- } \\
\text { gies (spinal tumors, cauda } \\
\text { equina syndrome, spinal frac- } \\
\text { ture, epilepsy, renal failure) }\end{array}$ \\
\hline \multicolumn{2}{|l|}{ Received nonsurgical management } \\
\hline \multicolumn{2}{|l|}{$\begin{array}{l}\text { Completion of pre- \& posttreatment } \\
\text { QOL outcomes questionnaires } \dagger\end{array}$} \\
\hline \multicolumn{2}{|c|}{$\begin{array}{l}\text { * Diagnosis of LSS, based on criteria such as gluteal and/or lower-extremity } \\
\text { pain and/or fatigue with or without back pain; symptoms aggravated by upright } \\
\text { exercise such as walking or positionally induced neurogenic claudication; and } \\
\text { symptomatic relief with forward flexion, sitting, or recumbency. } \\
\dagger \text { Posttreatment questionnaire was administered at } 4 \pm 2 \text { months after the } \\
\text { start of treatment. }\end{array}$} \\
\hline
\end{tabular}

score range from 0 to 27 . The total score is commonly categorized into one of five groups: Minimal (Score 0-4), Mild (Score 5-9), Moderate (Score 10-14), Moderate-Severe (Score 15-19), and Severe (Score 20-27). The PHQ9 has been validated as a measure of depression in large multicenter analyses..$^{27,28}$

Outcome measures were based on the posttreatment follow-up PDQ and EQ-5D scores. The PDQ evaluates chronic disabling musculoskeletal and spinal disorders, focuses on disability and patients' ability to perform activities of daily living, and ranges from 0 (optimal function) to 150 (total disability). The EQ-5D contains 5 dimensions of the health state, each scored from 1 to 3: Mobility, SelfCare, Usual Activities, Pain/Discomfort, and Anxiety/Depression. The EQ-5D index was derived from the EQ-5D and is defined as a utility value in which perfect health is 1.0 and death is 0.0 ; anything between perfect health and death is assigned a utility value between 0.0 and 1.0.7,15,16,19

The QOL data that were obtained were compared with the minimum clinically important differences (MCIDs), which are patient-derived health outcome scores for different QOL measures that reflect the minimum change in QOL necessary to elicit meaningful improvement for the patient. The MCID used for each questionnaire was 16 for the PDQ and 0.1 for the EQ-5D index. ${ }^{23,24,32}$

\section{Statistical Methods}

Summary statistics were computed for all patients using R software, version 2.15.13 (R Core Team, 2013). To examine the association between baseline depression and change in QOL, we created a mixed-effects linear regression model in which 4-month follow-up EQ-5D index or PDQ score was the dependent variable. The independent variable was the pretreatment PHQ-9 score. We adjusted for the following covariates measured at the visit before treatment: baseline EQ-5D index (or PDQ), age, sex, race, body mass index (BMI), insurance status, median household income in US dollars, percent below poverty level, and percent with a bachelor's degree or higher. In addition, a random effect for physician was used to account for correlated responses within a group treated by a single physi- 
cian. Using these methods, we significantly decreased the possibility of bias and confounding from baseline characteristics. Statistical significance was set at $\mathrm{p}=0.05$.

\section{Results}

A total of 502 patients were identified based on inclusion and exclusion criteria. Of these, 490 patients had completed the EQ-5D and 283 had completed the PDQ both before and after treatment. Summary statistics for all patients are provided in Table 2 . The average age was 66.1 years, average BMI was $29.3,51 \%$ (256 of 502) were female, and $90.6 \%$ (455 of 502) were white. Table 3 provides a statistical comparison of patients with and without depression as defined by a PHQ-9 score of 10 or higher (depressed).

Table 4 displays the pre- and posttreatment QOL scores for all patients. Before treatment, average EQ-5D index improved from 0.61 to 0.68 , and average PDQ improved from 65.3 to 60.6 . Of the 490 patients who completed the EQ-5D survey pre- and posttreatment, $265(54.1 \%)$ had at least some improvement in EQ-5D index, and 170 (34.7\%) had improvement that exceeded the MCID. Of the 283 patients who completed the PDQ both before and after treatment, $152(53.7 \%)$ had at least some improvement and 76 (26.9\%) had improvement exceeding the MCID.

After adjusting for the effects of baseline EQ-5D index and patient demographic and clinical variables, there was a significant association between baseline PHQ-9 depression score and 4-month follow-up EQ-5D index ( $\mathrm{p}=$ 0.0002). For each point higher in baseline PHQ-9 score (worsening depression), the change in EQ-5D index decreased by 0.007 points $(95 \% \mathrm{CI}-0.011$ to -0.003$)$. This indicates that, with all other things being equal, a patient with a baseline PHQ-9 score of 0 (no depression) would be expected to have a 4-month follow-up EQ-5D index that was 0.14 points higher than a patient with a baseline PHQ-9 score of 20 (severe depression). Figure 1 displays a plot of predicted 4-month follow-up EQ-5D index values across the range of possible baseline PHQ-9 scores for the average patient. These predicted values were calculated by inputting the average values for each continuous variable into the regression equation and by taking weighted averages of the regression coefficients of the categorical variables. When adjusting for the effects of patient demographic and clinical variables, there was no significant association between baseline PHQ-9 score and change in PDQ $(\beta=0.44,95 \%$ CI -0.26 to $1.14 ; p=0.2)$.

\section{Discussion}

The incidence of LSS increases throughout life and impacts both daily function and QOL. Surgery is a mainstay treatment, with LSS being the most common reason for lumbar spine surgery in adults older than 65 years. ${ }^{30}$ The Spine Patient Outcomes Research Trial (SPORT) as well as other studies revealed that surgery leads to superior pain and function outcomes compared with nonoperative management. ${ }^{22,30,31}$ The intention-to-treat analysis of SPORT, however, showed no difference between the 2 groups in function and disability, and all analyses revealed no significant worsening with nonsurgical therapy. ${ }^{6,30}$ Clinically,
TABLE 2. Summary statistics for patients included in analysis*

\begin{tabular}{|c|c|}
\hline Characteristic & Value \\
\hline No. of patients & 502 \\
\hline Age in yrs & $66.1 \pm 9.6$ \\
\hline $\mathrm{BMI}$ & $29.3 \pm 6.2$ \\
\hline \multicolumn{2}{|l|}{ Sex } \\
\hline Male & $246(49 \%)$ \\
\hline Female & $256(51 \%)$ \\
\hline \multicolumn{2}{|l|}{ Race } \\
\hline White & $455(90.6 \%)$ \\
\hline Black & $24(4.8 \%)$ \\
\hline Other & $8(1.6 \%)$ \\
\hline \multicolumn{2}{|l|}{ Marital status } \\
\hline Married & $362(72.1 \%)$ \\
\hline Single & $44(8.8 \%)$ \\
\hline Divorced & $40(8.0 \%)$ \\
\hline Widowed & $54(10.8 \%)$ \\
\hline \multicolumn{2}{|l|}{ Insurance status } \\
\hline Private/other & $301(60 \%)$ \\
\hline Medicare & $191(38 \%)$ \\
\hline Medicaid & $5(1 \%)$ \\
\hline Below poverty & $9.9 \%$ \\
\hline Education (bachelor's degree) & $30.4 \%$ \\
\hline Median household income (\$) & $59,000 \pm 16,700$ \\
\hline PHQ-9 (baseline) & $6.8 \pm 5.9$ \\
\hline EQ-5D index (baseline) & $0.61 \pm 0.21$ \\
\hline PDQ (baseline) & $65.3 \pm 29.7$ \\
\hline
\end{tabular}

* Results are displayed as the mean $\pm \mathrm{SD}$ or number (percent) as appropriate.

many patients prefer conservative treatment or have comorbidities that preclude surgical treatments. Moreover, because surgery is associated with greater cost and complications, it is important to identify both the conservative measures that can improve QOL outcomes and also the patients most likely to benefit from these treatments.

A priori identification of patients most likely to improve following spine surgery has been increasingly investigated. Particularly, depression has been shown to be associated with less improvement following lumbar fusion surgery. ${ }^{1-3,5,9,26,29}$ There are very few such studies, however, with regard to medical management of LSS. Karp and colleagues $^{18}$ reviewed 158 patients who underwent epidural spinal injections for low-back pain with or without radiculopathy. These investigators found that depression and sleep disturbance were prognostic of worse PatientReported Outcome Measurement Information System (PROMIS) outcomes following epidural spinal injections. Hägg et al. ${ }^{13}$ performed a randomized controlled trial of 264 patients with severe chronic low-back pain who underwent either surgical or nonsurgical treatment, and assessed the impact of underlying affective disorders. They found that baseline depression correlated with worse outcomes following both operative and nonoperative treatment. Interestingly, they also observed that depressed patients tended to have better outcomes with nonoperative 
TABLE 3. Dichotomized comparison of depressed versus nondepressed patients*

\begin{tabular}{|c|c|c|c|}
\hline Characteristic & Depressed & $\begin{array}{c}\text { Non- } \\
\text { depressed }\end{array}$ & $p$ Value \\
\hline No. of patients & 108 & 303 & \\
\hline Age in yrs & $63.9 \pm 9.5$ & $66.6 \pm 9.3$ & 0.0125 \\
\hline BMI & $30.6 \pm 7$ & $28.7 \pm 5.9$ & 0.0763 \\
\hline \multicolumn{4}{|l|}{ Sex } \\
\hline Male & $50(46.3 \%)$ & $147(48.5 \%)$ & 0.7106 \\
\hline Female & $58(53.7 \%)$ & $156(51.5 \%)$ & \\
\hline \multicolumn{4}{|l|}{ Race } \\
\hline White & $92(85.2 \%)$ & $281(92.7 \%)$ & 0.0340 \\
\hline Black & $9(8.3 \%)$ & $9(3.0 \%)$ & \\
\hline Other & $2(1.9 \%)$ & $4(1.3 \%)$ & \\
\hline \multicolumn{4}{|l|}{ Marital status } \\
\hline Married & $79(73.1 \%)$ & $219(72.3 \%)$ & 0.8716 \\
\hline Single & $9(8.3 \%)$ & $28(9.2 \%)$ & \\
\hline Divorced & $10(9.3 \%)$ & $22(7.3 \%)$ & \\
\hline Widowed & $10(9.3 \%)$ & $33(10.9 \%)$ & \\
\hline \multicolumn{4}{|l|}{ Insurance status } \\
\hline Private/other & $77(71.3 \%)$ & $174(57.4 \%)$ & 0.0345 \\
\hline Medicare & $28(25.9 \%)$ & $124(40.9 \%)$ & \\
\hline Medicaid & $1(0.9 \%)$ & $2(0.7 \%)$ & \\
\hline Below poverty & $12.2 \%$ & $9.0 \%$ & 0.0001 \\
\hline Education (bachelor's degree) & $27.3 \%$ & $31.2 \%$ & 0.0175 \\
\hline Median income $(\times \$ 1000)$ & $54.3 \pm 17.1$ & $60.5 \pm 15.9$ & 0.0002 \\
\hline PHQ-9 (baseline) & $15 \pm 4.4$ & $3.8 \pm 2.8$ & $<0.0001$ \\
\hline EQ-5D index (baseline) & $0.45 \pm 0.18$ & $0.66 \pm 0.19$ & $<0.0001$ \\
\hline PDQ (baseline) & $89.2 \pm 23.1$ & $52.4 \pm 26.0$ & $<0.0001$ \\
\hline
\end{tabular}

* Summary statistics for patients in the final cohort identified as depressed (PHQ-9 $\geq 10$ ) or not (PHQ-9 $<10)$ according to their baseline PHQ-9 score. Results are displayed as the mean \pm SD or number (percent) as appropriate. The $p$ values for continuous variables were obtained using Mann-Whitney U-tests. The Fisher exact test was used for categorical variables. Although the groups were dichotomized for this comparison, for the regression analysis PHQ-9 was used as a continuous score.

care, whereas nondepressed patients tended to have better outcomes with fusion. ${ }^{11,13}$

In the present study, we found that worsening depression (as measured by the PHQ-9) independently significantly predicted worse EQ-5D index outcomes following conservative treatment for LSS $(p=0.0002)$. This effect was most evident when comparing patients with severe depression, who improve 0.14 points less than those with no depression. This difference exceeds the MCID and confirms that depression is a poor prognostic factor for QOL improvement following nonoperative treatment for LSS. Further investigation is needed to determine whether treatment of depression prior to conservative or surgical management of LSS will improve posttreatment QOL outcomes.

There are several limitations that should be considered when interpreting the results. Multiple treating physicians were included, and factors such as participation in physical therapy, treatment with NSAIDs, opioid medications,
TABLE 4. Improvement in QOL according to EQ-5D and PDQ measures*

\begin{tabular}{lc}
\hline \multicolumn{1}{c}{ Variable } & Value \\
\hline EQ-5D index & \\
\hline Pretreatment & $0.61 \pm 0.21$ \\
\hline Posttreatment & $0.68 \pm 0.21$ \\
\hline Any improvement & $265(54.1 \%)$ \\
\hline Improvement $>$ MCID & $170(34.7 \%)$ \\
\hline Effect $(95 \%$ CI) $\dagger$ & $-0.007(-0.011$ to -0.003$) ; p=0.0002$ \\
\hline PDQ & \\
\hline Pretreatment & $65.3 \pm 29.7$ \\
\hline Posttreatment & $60.6 \pm 32.9$ \\
\hline Any improvement & $152(53.7 \%)$ \\
\hline Improvement $>$ MCID & $76(26.9 \%)$ \\
\hline Effect $(95 \%$ CI) $\dagger$ & $0.44(-0.26$ to 1.14$) ; p=0.2136$ \\
\hline
\end{tabular}

${ }^{*}$ Results are displayed as the mean \pm SD or number (percent) as appropriate. $\dagger$ Effect $(95 \% \mathrm{Cl})$ of and $p$ values for each 1-unit increase in PHQ-9 score on 4-month follow-up score (EQ-5D index or PDQ total score). Effects have been adjusted for age, BMI, sex, race, marital status, insurance status, \% below poverty, \% with a bachelor's degree, and baseline EQ-5D index or PDQ total score.

and other nonsurgical treatments varied by practitioner and patient; this increases the variability, but also improves the generalizability. We adjusted for the increased variability by using the random effect in the regression models. Many patients were also lost to follow-up at the 4-month evaluation. To assess for bias, Table 5 provides summary statistics comparing the study cohort and the cohort lost to follow-up. The cohorts were similar for most characteristics; however, there were statistically significant, albeit small differences for estimated percent below poverty threshold and median income by zip code. Our analysis is only valid for patients who did follow-up assessments at these time points. Additionally, this was a ret-

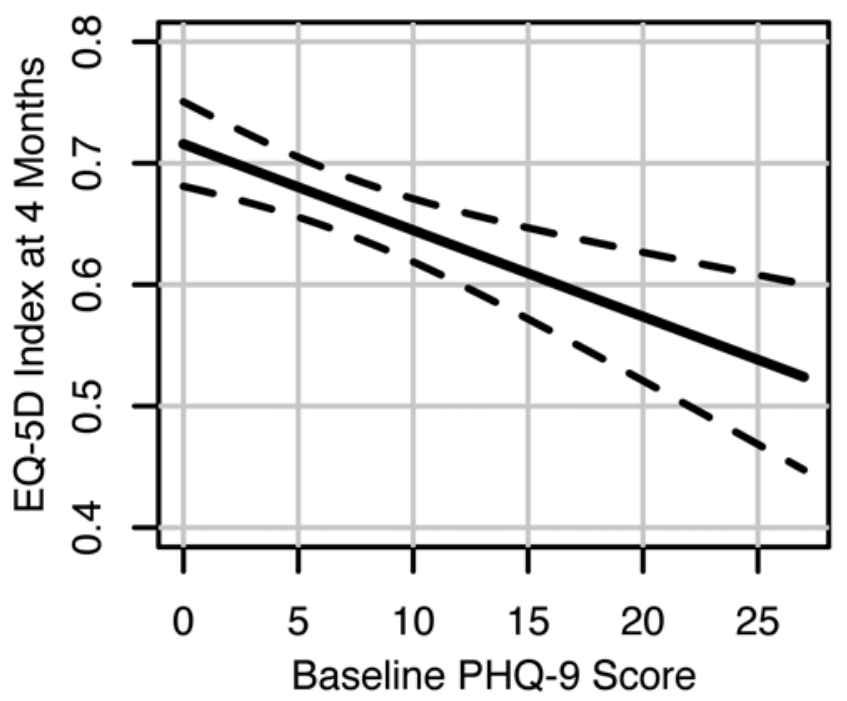

FIG. 1. Graph showing the predicted mean change in EQ-5D index by baseline PHQ-9 score for the average patient. The dashed lines represent a $95 \%$ confidence band. 
TABLE 5. Summary statistics for patients lost to follow-up and the final cohort*

\begin{tabular}{|c|c|c|c|}
\hline Characteristic & $\begin{array}{l}\text { Lost to } \\
\text { Follow-Up }\end{array}$ & Final Cohort & $p$ Value \\
\hline No. of patients & 2004 & 502 & \\
\hline Age in yrs & $67.1 \pm 10.4$ & $66.1 \pm 9.6$ & 0.0788 \\
\hline BMI & $29.5 \pm 6.4$ & $29.3 \pm 6.2$ & 0.9579 \\
\hline \multicolumn{4}{|l|}{ Sex } \\
\hline Male & $1035(51.6 \%)$ & $246(49.0 \%)$ & 0.2949 \\
\hline Female & $969(48.4 \%)$ & $256(51.0 \%)$ & \\
\hline \multicolumn{4}{|l|}{ Race } \\
\hline White & $1767(88.2 \%)$ & $455(90.6 \%)$ & 0.3288 \\
\hline Black & $118(5.9 \%)$ & $24(4.8 \%)$ & \\
\hline Other & $20(1.0 \%)$ & $8(1.6 \%)$ & \\
\hline \multicolumn{4}{|l|}{ Marital status } \\
\hline Married & $1359(67.8 \%)$ & $362(72.1 \%)$ & 0.4998 \\
\hline Single & $213(10.6 \%)$ & $44(8.8 \%)$ & \\
\hline Divorced & $167(8.3 \%)$ & $40(8.0 \%)$ & \\
\hline Widowed & $219(10.9 \%)$ & $54(10.8 \%)$ & \\
\hline \multicolumn{4}{|l|}{ Insurance status } \\
\hline Private/other & $1110(55.4 \%)$ & $301(60.0 \%)$ & 0.9445 \\
\hline Medicare & $727(36.3 \%)$ & $191(38.0 \%)$ & \\
\hline Medicaid & $17(0.8 \%)$ & $5(1.0 \%)$ & \\
\hline Below poverty & $10.8 \%$ & $9.9 \%$ & 0.0042 \\
\hline Education (bachelor's degree) & $29.9 \%$ & $30.4 \%$ & 0.2579 \\
\hline Median income $(\times \$ 1000)$ & $56.9 \pm 18.3$ & $59 \pm 16.7$ & 0.0021 \\
\hline PHQ-9 (baseline) & $6.8 \pm 6.0$ & $6.8 \pm 5.9$ & 0.8795 \\
\hline EQ-5D index (baseline) & $0.6 \pm 0.22$ & $0.61 \pm 0.21$ & 0.4809 \\
\hline PDQ (baseline) & $65.7 \pm 32.4$ & $65.3 \pm 2.97$ & 0.8663 \\
\hline
\end{tabular}

${ }^{*}$ Results are displayed as the mean $\pm \mathrm{SD}$ or number (percent) as appropriate. The $p$ values for continuous variables were obtained using Mann-Whitney U-tests. The Fisher exact test was used for categorical variables.

rospective study with a relatively short follow-up period. Prospectively designed studies with longer follow-up are needed to further validate the findings. Nonetheless, this is the largest study investigating the correlation between depression and QOL outcomes following conservative management of LSS. We have used the validated PHQ-9 measure of depression ${ }^{10}$ and have found a statistically and clinically significant impact on EQ-5D index outcomes.

\section{Conclusions}

The results of this study suggest that depressed patients with LSS have significantly less improvement following conservative management compared with nondepressed patients. Both physicians and surgeons who treat patients with LSS should consider using validated questionnaires such as the PHQ-9 for pretreatment evaluation of depression, to better assess the likelihood of success following treatment. Further investigation is needed to evaluate the effect of depression treatment prior to management of the spinal disorder. Future prospective studies with longer follow-up intervals may be useful in further evaluating the QOL outcomes in this patient population.

\section{References}

1. Aalto TJ, Malmivaara A, Kovacs F, Herno A, Alen M, Salmi L, et al: Preoperative predictors for postoperative clinical outcome in lumbar spinal stenosis: systematic review. Spine (Phila Pa 1976) 31:E648-E663, 2006

2. Adogwa O, Parker SL, Shau DN, Mendenhall SK, Aaronson OS, Cheng JS, et al: Preoperative Zung Depression Scale predicts outcome after revision lumbar surgery for adjacent segment disease, recurrent stenosis, and pseudarthrosis. Spine J 12:179-185, 2012

3. Adogwa O, Parker SL, Shau DN, Mendenhall SK, Bydon A, Cheng JS, et al: Preoperative Zung depression scale predicts patient satisfaction independent of the extent of improvement after revision lumbar surgery. Spine J 13:501-506, 2013

4. Appaduray SP, Lo P: Effects of diabetes and smoking on lumbar spinal surgery outcomes. J Clin Neurosci 20:17131717,2013

5. Arpino L, Iavarone A, Parlato C, Moraci A: Prognostic role of depression after lumbar disc surgery. Neurol Sci 25:145147, 2004

6. Asghar FA, Hilibrand AS: The impact of the Spine Patient Outcomes Research Trial (SPORT) results on orthopaedic practice. J Am Acad Orthop Surg 20:160-166, 2012

7. Badia X, Diaz-Prieto A, Gorriz MT, Herdman M, Torrado H, Farrero E, et al: Using the EuroQol-5D to measure changes in quality of life 12 months after discharge from an intensive care unit. Intensive Care Med 27:1901-1907, 2001

8. Celestin J, Edwards RR, Jamison RN: Pretreatment psychosocial variables as predictors of outcomes following lumbar surgery and spinal cord stimulation: a systematic review and literature synthesis. Pain Med 10:639-653, 2009

9. Chaichana KL, Mukherjee D, Adogwa O, Cheng JS, McGirt MJ: Correlation of preoperative depression and somatic perception scales with postoperative disability and quality of life after lumbar discectomy. J Neurosurg Spine 14:261267, 2011

10. Choi YH, Mayer TG, Williams MJ, Gatchel RJ: What is the best screening test for depression in chronic spinal pain patients? Spine J 14:1175-1182, 2014

11. Daubs MD, Norvell DC, McGuire R, Molinari R, Hermsmeyer JT, Fourney DR, et al: Fusion versus nonoperative care for chronic low back pain: do psychological factors affect outcomes? Spine (Phila Pa 1976) 36 (21 Suppl):S96S109, 2011

12. Gatchel RJ, Mayer TG, Theodore BR: The pain disability questionnaire: relationship to one-year functional and psychosocial rehabilitation outcomes. J Occup Rehabil 16:7594, 2006

13. Hägg O, Fritzell P, Ekselius L, Nordwall A: Predictors of outcome in fusion surgery for chronic low back pain. A report from the Swedish Lumbar Spine Study. Eur Spine J 12:22-33, 2003

14. Jansson KA, Németh G, Granath F, Jönsson B, Blomqvist P: Health-related quality of life (EQ-5D) before and one year after surgery for lumbar spinal stenosis. J Bone Joint Surg Br 91:210-216, 2009

15. Jansson KA, Németh G, Granath F, Jönsson B, Blomqvist P: Health-related quality of life in patients before and after surgery for a herniated lumbar disc. J Bone Joint Surg Br 87:959-964, 2005

16. Johnson JA, Coons SJ, Ergo A, Szava-Kovats G: Valuation of EuroQOL (EQ-5D) health states in an adult US sample. Pharmacoeconomics 13:421-433, 1998

17. Kalichman L, Cole R, Kim DH, Li L, Suri P, Guermazi A, et al: Spinal stenosis prevalence and association with symptoms: the Framingham Study. Spine J 9:545-550, 2009

18. Karp JF, Yu L, Friedly J, Amtmann D, Pilkonis PA: Negative affect and sleep disturbance may be associated with response 
to epidural steroid injections for spine-related pain. Arch Phys Med Rehabil 95:309-315, 2014

19. Kepler CK, Wilkinson SM, Radcliff KE, Vaccaro AR, Anderson DG, Hilibrand AS, et al: Cost-utility analysis in spine care: a systematic review. Spine J 12:676-690, 2012

20. Kroenke K, Spitzer RL, Williams JB: The PHQ-9: validity of a brief depression severity measure. J Gen Intern Med 16:606-613, 2001

21. LaCaille RA, DeBerard MS, Masters KS, Colledge AL, Bacon W: Presurgical biopsychosocial factors predict multidimensional patient: outcomes of interbody cage lumbar fusion. Spine J 5:71-78, 2005

22. Malmivaara A, Slätis P, Heliövaara M, Sainio P, Kinnunen H, Kankare J, et al: Surgical or nonoperative treatment for lumbar spinal stenosis? A randomized controlled trial. Spine (Phila Pa 1976) 32:1-8, 2007

23. Norman GR, Sloan JA, Wyrwich KW: Interpretation of changes in health-related quality of life: the remarkable universality of half a standard deviation. Med Care 41:582-592, 2003

24. Parker SL, Godil SS, Shau DN, Mendenhall SK, McGirt MJ: Assessment of the minimum clinically important difference in pain, disability, and quality of life after anterior cervical discectomy and fusion. Clinical article. J Neurosurg Spine 18:154-160, 2013

25. Parker SL, Mendenhall SK, Shau D, Adogwa O, Cheng JS, Anderson WN, et al: Determination of minimum clinically important difference in pain, disability, and quality of life after extension of fusion for adjacent-segment disease. J Neurosurg Spine 16:61-67, 2012

26. Sinikallio S, Aalto T, Airaksinen O, Herno A, Kröger H, Viinamäki H: Depressive burden in the preoperative and early recovery phase predicts poorer surgery outcome among lumbar spinal stenosis patients: a one-year prospective follow-up study. Spine (Phila Pa 1976) 34:2573-2578, 2009

27. Spitzer RL, Kroenke K, Williams JB: Validation and utility of a self-report version of PRIME-MD: the PHQ primary care study. Primary Care Evaluation of Mental Disorders. Patient Health Questionnaire. JAMA 282:1737-1744, 1999

28. Spitzer RL, Williams JB, Kroenke K, Hornyak R, McMurray J: Validity and utility of the PRIME-MD patient health questionnaire in assessment of 3000 obstetric-gynecologic patients: the PRIME-MD Patient Health Questionnaire Obstetrics-Gynecology Study. Am J Obstet Gynecol 183:759-769, 2000

29. Trief PM, Grant W, Fredrickson B: A prospective study of psychological predictors of lumbar surgery outcome. Spine (Phila Pa 1976) 25:2616-2621, 2000

30. Weinstein JN, Lurie JD, Tosteson TD, Hanscom B, Tosteson ANA, Blood EA, et al: Surgical versus nonsurgical treatment for lumbar degenerative spondylolisthesis. N Engl J Med 356:2257-2270, 2007

31. Weinstein JN, Tosteson TD, Lurie JD, Tosteson A, Blood E, Herkowitz H, et al: Surgical versus nonoperative treatment for lumbar spinal stenosis four-year results of the Spine Patient Outcomes Research Trial. Spine (Phila Pa 1976) 35:1329-1338, 2010

32. Wilson HD: Minimum Clinical Important Differences of Health Outcomes in a Chronic Pain Population: Are They Predictive of Poor Outcomes? [dissertation]. Arlington: University of Texas at Arlington, 2008

\section{Author Contributions}

Conception and design: Khalaf, Lubelski. Acquisition of data: Thompson. Analysis and interpretation of data: all authors. Drafting the article: Lubelski, Thompson. Critically revising the article: all authors. Reviewed submitted version of manuscript: all authors. Statistical analysis: Lubelski, Thompson.

\section{Correspondence}

Tagreed Khalaf, Center for Spine Health, Cleveland Clinic, 9500 Euclid Ave., S-40, Cleveland, OH 44195. email: khalaft@ccf.org. 